\title{
Methodological and practical viewpoints of qualitative-driven mixed method design: the case of decentralisation of primary healthcare services in Nepal
}

\section{Krishna Regmi}

Faculty of Health and Social Sciences, Institute for Health Research, University of Bedfordshire, Luton, UK

\begin{abstract}
Background: Although considerable attention has been paid to the use of quantitative methods in health research, there has been limited focus on decentralisation research using a qualitative-driven mixed method design. Decentralisation presents both a problematic concept and methodological challenges, and is more context-specific and is often multidimensional. Researchers often consider using more than one method design when researching phenomena is complex in nature. Aim: To explore the effects of decentralisation on the provision of primary healthcare services. Methods: Qualitative-driven mixed method design, employing three methods of data collections: focus group discussions (FGDs), semi-structured interviews (SSIs) and participant observations under two components, that is, core component and supplementary components were used. Four FGDs with health service practitioners, three FGDs with district stakeholders, $20 \mathrm{SSIs}$ with health service users and 20 SSls with national stakeholders were carried out. These were conducted sequentially. NVivo10, a data management program, was utilised to code the field data, employing a content analysis method for searching the underlying themes or concepts in the text material. Findings: Both positive and negative experiences related to access, quality, planning, supplies, coordination and supervision were identified. Conclusion: This study suggests some evidence of the effects of decentralisation on health outcomes in general, as well as filling a gap of understanding and examining healthcare through a qualitative-driven mixed methods approach, in particular. Future research in the area of qualitative in-depth understanding of the problems (why decentralisation, why now and what for) would provoke an important data set that benefits the researchers and policy-makers for planning and implementing effective health services.
\end{abstract}

Key words: decentralisation; health services; primary healthcare; qualitative-driven mixed method

Received 7 October 2016; revised 23 July 2017; accepted 3 August 2017; first published online 11 September 2017

\section{Background}

The World Health Organisation recommends that the multiple facets of healthcare should be

Correspondence to: Krishna Regmi, Faculty of Health and Social Sciences, Institute for Health Research, University of Bedfordshire, Luton LU2 8LE, UK. Email: Krishna.r. regmi@gmail.com appropriately understood before making any healthcare interventions (Roberts et al., 2004). Despite a growing need to engage in health- and health systems-related research, there is still limited evidence of theoretical and methodological underpinnings about qualitative design in this area (Green and Thorogood, 2014).

Patton (2002) suggested that qualitative methods in primary healthcare (PHC) research would be

(C) Cambridge University Press 2017 
appropriate to meet the needs and interests of decision-makers and healthcare practitioners by providing an in-depth understanding of complex health problems, which ultimately would be useful in health planning and management. In the same vein, Morse agreed that 'qualitative [approaches] often address broad and complex problems rather than the concise hypotheses found in quantitative' designs (2003: 834). In Green and Thorogood's (2014: xiv) view, one of the limitations of current approaches to generating qualitative evidence for $\mathrm{PHC}$ research is a lack of relevant and appropriate study design, as 'the context of health research may be rather different from that of general social research'. To address these concerns, and add to the literature on health research, this paper uses qualitative-driven mixed method to explore the effects of decentralisation on provision of $\mathrm{PHC}$ services in the context of Nepal.

\section{Methods}

\section{Setting}

Nepal is one of the poorest countries of South Asia. Despite expanding the universal healthcare services through PHC settings to the rural communities, difficult topography (hills and mountains) and political instability have meant that Nepal has consistency failed to achieve a lasting change in improving people's health status. Accessing and utilising essential PHC, mainly for poor and marginalised people, remains a challenge. Revitalisation of PHC, through improving health access, reducing health inequities, and addressing new challenges and expectations by ensuring high quality, has been put forward as an immediate agenda of the government (Department of Health Services, 2014).

Between 2007 and 2010, I conducted study on decentralisation, a system which involves the transfer of central governments' resources with authority, accountability and responsibility to local tiers of government. Imbued in the notion of decentralisation is the belief that local is better in terms of identifying, analysing and implementing appropriate government actions (Regmi et al., 2010). Over four decades, decentralisation has been adapted to reform health services across the globe, and Nepal has also adopted this approach to reform its PHC services.
There is, however, little exploration concerning the impact of decentralisation policy on health service performance, mainly due to the complex nature of the subject matter, as well as methodological challenges. Qualitative design in health research can assist in filling this gap.

\section{Methodological justification}

Although there are no clear-cut divisions between quantitative and qualitative paradigms, and they are not mutually exclusive; quantitative research provides a more generalised and numerically based view of reality, allegedly neglecting social and cultural meanings (Patton, 2002; Silverman, 2010). Broadly conceived, qualitative methodology encompasses a variety of methods, which are characteristically languagebased, descriptive rather than analytical, and which, to varying degrees, recognise the experience of the researcher as a significant variable in the form of the data collected (Seale et al., 2004).

Flick (1998: 4) emphasised that 'recognition and analysis of different perspectives, researchers' reflections on their research as part of the process of knowledge production, and the range of approaches and methodology' are important aspects of qualitative research. Qualitative methods, therefore, would be a preferred method for research design "when little is known about the topic, when research context is poorly understood, when the boundaries of the domain are ill-defined, when the phenomenon is not quantifiable, [or] when the nature of the problem is murky' (Morse, 2003: 833).

Based on the above criteria, qualitative methodology is a good fit for the present study. First, there have been some attempts to measure the impact of decentralisation through allocation of public expenses and revenues (fiscal decentralisation) using quantitative attributes (Porcelli, 2009; Jiménez-Rubio, 2011) approaches would present a great challenge. According to Bossert (2014), measuring decentralisation is more about who gets more choice (deconcentration or devolution), and how much choice (narrow, moderate or broad) is given to local authorities over what functions (financing, service delivery, human resources, access rules and governance), rather than an association of independent and dependent variables or causal relationships. This is mainly due to two

Primary Health Care Research \& Development 2018; 19: 64-76 
challenges: (i) problematic concept, as different disciplines (political science, social policy, management, development studies, geography) use the term decentralisation and it appears in different conceptual literatures (federalism, central-local relations, principal-agent theory, public choice theory). Therefore, the concept of decentralisation is difficult to measure and link to the conceptual literature (Peckham et al., 2006). And (ii) methodological problem, as there is limited evidence available 'that developed systematic definitions, conceptual frameworks and consistent methodologies to produce consistent, valid and reliable results' (Bossert, 1996: 149). In addition, the nature of decentralisation is context-specific and is often multi-dimensional, therefore it has been suggested that the effects of decentralisation, even within a country, would be different (Litvack et al.,1998).

Second, measuring the impact of decentralisation is a complex phenomenon, as health systems across the world are constantly changing, and how radically the change departs from past practice can often be difficult to measure in quantitative attributes (Roberts et al., 2004). Third, the meaning and interpretation of decentralisation is ill-defined and it is recommended to understand its meaning through utilising stakeholders' knowledge within their context, mechanisms, and expected outcomes (Pawson and Tilly, 1997). Finally, evaluating the impact of health services, mainly in low- and middle-income countries, is often difficult due to the lack of reliable data systems, and traditional (quantitative) research may no longer be appropriate for addressing complex PHC interventions (World Health Organization, 2014).

\section{Techniques, tools and approaches}

The meaning and interpretations of mixed methods are debatable and this often creates some confusion over the way the term has been used in the research literature or paradigms. Cheek et al. (2015) argue that people often used the terms 'mixed methods', 'mixed method research' and 'multiple methods' interchangeably. In fact, these terms do not have the same meanings. Several authors argue that the term 'mixed methods' has consistently brought ambiguity, confusions and lack of precision (Johnson et al., 2007; Hesse-Biber, 2010; Hesse-Biber and Johnson, 2013; Morse and Cheek, 2014; Cheek et al., 2015). Greene (2006)

Primary Health Care Research \& Development 2018; 19: 64-76 warns that one of the challenges of using mixed methods research is not only the meaning and interpretation of qualitative and quantitative, but also the fact that they belong to different and incompatible paradigms. In such a context, Morse and Niehaus pose a question on 'how researcher combines the qualitative and quantitative components in a single project as an essential consideration if rigour is to be maintained' (2009: 19). It can be argued that the issue of incompatibility in mixed methods is always debatable, either due to the disciplinary devaluation of the qualitative component (Creswell et al., 2006) or devaluation of anything less than experimental designs (Denzin and Lincoln, 2005). Another practical challenge is that there is no specific tool or technique that would be able to measure or evaluate the impact of mixed methods designs precisely (Morse and Niehaus, 2009). Some commentators have questioned whether using both qualitative and quantitative criteria would be the best approach to evaluating the mixed methods (Sale and Brazil, 2004), but others see the validity 'legitimation' is the critical component beyond the sum of its parts (Onwuegbuzie and Johnson, 2006).

Generally, mixed methods are considered as a combination of qualitative and quantitative methods that were mixed, but here we have clearly seen the complexity and difficulty involved in the combination. According to Morse and Niehaus (2009), a mixed methods study 'consists of a qualitative or quantitative core component and a supplementary component (which consists of qualitative or quantitative research strategies but is not a complete study in itself)'. This design would also consider 'mix[ing] two qualitative methods or two quantitative methods' (Morse and Niehaus, 2009: 20). It is interesting to emphasise that the notion of mixed methods is not only mixing two or more approaches or their parts in a single study, but also it is the point of interface of those approaches and the consequent integration of the results of the various components in the research ... such integration is the key in mixed designs, both to the design and to the significance of the study' (Morse and Cheek, 2015: 731).

Due to different theoretical drives, that is, the conceptual direction or overall purpose of the research, as well as a combination of both core and supplementary components, qualitative-driven mixed methods can possibly be categorised into four designs (Table 1). 
Given the objectives and significance of the study, I decided to adopt a qualitative-driven mixed methods design QUAL $\rightarrow$ qual. The study design, adapted from Morse and Niehaus's (2009) qualitative-driven mixed methods research, has been represented in Figure 1.

I obtained data through three methods of data collections: focus group discussions (FGDs), semistructured interviews (SSIs) and participant observations (POs), where the QUAL core component was the FGDs and the supplementary components were SSIs and POs. These were conducted sequentially, not only to obtain two different perspectives on the same phenomenon, but also to integrate the supplementary findings with the core component. From the SSIs, I hoped to understand the individuals' perspectives and perceptions; from the POs, I wanted to contextualise the relationship between stakeholders; and from the FGDs, I hoped to see the participants' knowledge and perspectives (perceptions, beliefs, experience), and some degree of inter-relationships. Morgan (1998) and Phillips et al. (2014) argued that one of the advantages of

Table 1 Qualitative-driven mixed method designs

\begin{tabular}{ll}
\hline CORE supplementary & Features \\
\hline QUAL + qual & $\begin{array}{c}\text { Qualitative core and qualitative supplementary components of the research are conducted } \\
\text { simultaneously } \\
\text { Qualitative core and qualitative supplementary components of the research are conducted } \\
\text { sequentially }\end{array}$ \\
Qualitative core and quantitative supplementary components of the research are conducted \\
Qumulaneously \\
Qualitative core and quantitative supplementary components of the research are conducted \\
sequentially
\end{tabular}

Source: Adapted from Morse and Niehaus (2009: 25)

Central research AIM/ISSUE: To explore the effects of decentralisation on provision of primary healthcare services

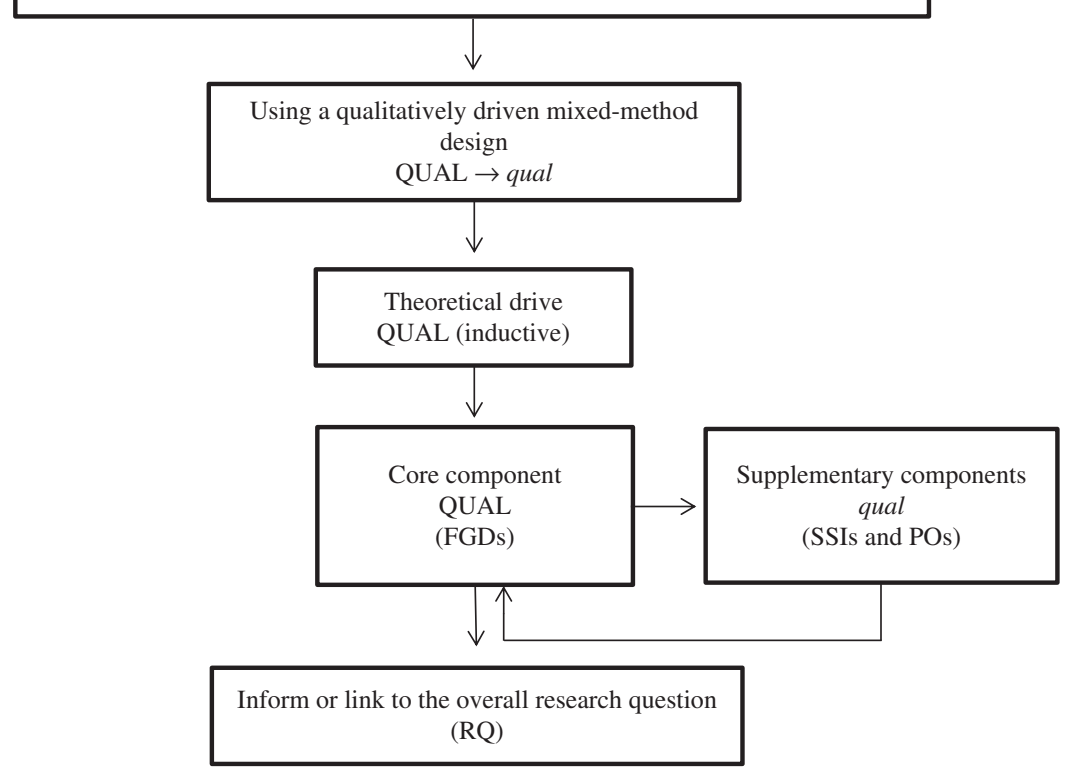

Figure 1 Research design. FGDs = focus group discussions; SSIs = semi-structured interviews; POs = participant observations 
using multiple methods with multiple groups is that it allows a comparison of similarities. Additionally, according to Morse and Niehaus, 'each qualitative method has particular questions that it may answer better than other qualitative methods' (2009: 111).

In sum, as set out above, this research was mainly focussed on the collection of qualitative information, adopting an exploratory and interpretative approach to investigate a particular phenomenon, related to the decentralisation of health services in Nepal. The data were collected through FGDs, SSIs and POs, engaging myself in the research via an iterative process (Chambers, 1997).

\section{Issues of sampling}

The quality of research is often determined by the use of appropriate methodology, field instruments and suitability of the sampling strategy (Cohen et al., 2011). This research utilised a purposive sampling method. As Teddlie and $\mathrm{Yu}$ (2007) and Bowling (2009) discuss, a purposive sample is one of the non-random methods which is often used to obtain samples from a group of people, or a setting to be able to achieve representativeness, focussing on specific and unique issues or cases as well as generating a theory though collecting data from different sources. In this study, the process of recruitment (sampling) stopped when data saturation occurred and all concepts were generated (Ritchie and Lewis, 2003; Bowling and Ebrahim, 2005).

Sample frames were used to recruit service users, service providers and members of the management committee. Bowling (2009) notes that a sampling frame is a complete list of people or members from which the sample has been drawn. In this study, I utilised three registers, that is, patients, staff register and management committee, while recruiting those respondents purposively in order to represent the full range of demographical variables, for example, age, gender, professional (doctor, nurse). Mason (2002: 121) argues that while conducting qualitative research, researchers are perhaps 'not interested in the census view, or trying to conduct a broad sweep of everything, so much as focusing in one specific issue, process, phenomenon, and so on', as qualitative research is all about the 'depth, nuance

Primary Health Care Research \& Development 2018; 19: 64-76 and complexity, and understanding how these work in reality'. As Newell (1996) argues, the selection of an appropriate sample frame also increases reliability, because the samples will be more likely to reflect the defined population accurately if selected again by using the same method.

\section{Data collection}

\section{Focus groups}

Hennink (2007) and Silverman (2010) argued that the purpose of having group discussions is to capitalise on communication between the group members to generate data. Focus groups explicitly use group interaction to provide insights to the subject matter (Campbell and Holland, 1999; Hennink, 2007). Questions covered in the focus groups included the effect of decentralisation on health services, and how specific groups perceived the decentralisation of health service implementation and management in their area. To gather information, I conducted seven FGDs: four with health service providers (HSPs) and three with district health service management committees (comprising individuals with political involvement, local leaders and representatives from excluded and marginalised communities). Each focus group contained four to six individuals who were selected purposively.

\section{Interviews}

I conducted SSIs, employing interview guides derived from both theories and drew upon previous research studies about the topic (Bossert, 2000; Bossert and Beauvais, 2002; Collins and Omar, 2003; Omar et al., 2007). To ensure crosscase comparability, a SSI protocol was deemed more convenient than an unstructured one. The broader issue of decentralisation was divided into the issues representing the health system and quality of health services; for instance, on the issue of decision-making, questions were asked as to how decisions about health services were taken, who made the decisions, who was involved, and how they communicated with other health service users (HSUs). This breakdown was intended to simplify the issue to make respondents feel comfortable in responding. 
From a selection of 20 respondents, approximately five service users per study site from four PHC facilities were selected purposively, using the following general criteria to gain the widest representation:

- Geographical location of service users

- Caste and ethnic origin

- Wealth (these categories were developed with the help of health professionals and committee members of health service management)

- Sex (both male and female)

All interviews were tape-recorded after getting the respondents' approval. Participants' anonymity and confidentiality were protected throughout the study.

\section{Field visits and POs}

Mason (2002) argues that observation helps to generate data through the immersion of the researcher into the research context. I had ample opportunities to observe and participate in local events during my stay in the field, which helped me to understand local realities, behavioural patterns, culture and values. I took notes of each event, such as: what went well and why; what did not go well and why not? These data helped me to cross-check my research. In this study, I used more than one method of data collection (triangulation of the data) using FGDs and SSIs, field observation and reflective notes, involving different stakeholders to produce rich and detailed contextual findings. Such findings have not only explained the richer understanding of the same phenomenon - decentralisation of PHC - better, but also increase the validity and trustworthiness of the information by cross-checking different stakeholders' viewpoints (Denzin, 1978; O'Cathain et al., 2008; Green and Thorogood, 2014). Tylor and Bogdan (1998) discussed that in PO, the researcher needs to go deeper into the sociocultural setting of the community for an extended period, and make regular observations of behaviour and the pattern of decision-making in social areas, such as participation, decision-making, culture, norms and values. During the field research, I had some opportunities to live within the community so as to interact with its residents, asking open-ended questions based on the situational context to get respondents' unique views towards the local health services (Gray, 2004). In the community, I also took part in meetings and discussions about local concerns, contributing ideas and sharing my own experience and knowledge about particular issues with other members. I recorded my observations and reflections regarding these meetings in a field notebook.

\section{Data analysis}

Data were collected from FGDs, SSIs and POs of different stakeholders in the study area. With the consent of the study respondents, events in relation to field studies were recorded in a field notebook. Answers from the interviews were recorded using a digital voice recorder and then transcribed/translated. This information entailed the aspects of service access, utilisation and delivery, including the understanding and perceptions of respondents about decentralisation linked to health services performance.

The analysis of my qualitative interviews and discussions began at the start of the interview process. In this research, I decided to undertake a basic content analysis of the qualitative data (Denzin and Lincoln, 1998; Patton, 2002). A qualitative content analysis method searched for underlying themes in the text material, which contained information contributing to the theme of the research (Bowling and Ebrahim, 2005). The analysis used transcripts of the FGDs and SSIs, identifying key concepts and allocating codes to them. Using NVivo10, codes and sentences were grouped and compared according to concepts and themes.

\section{Issues of validity and reliability}

Validity, reliability and generalisability are often linked with authenticity and robustness of any research or research findings (Regmi, 2013). The degree of accuracy of the description of the phenomenon depends upon the subject, and the context of the study reflects the meaning of validity (Bryman, 2001; Gray, 2004). To attain validity and reliability, I adopted Mays and Pope's (1996) criteria: first, I produced a thorough and comprehensive account of the phenomenon under scrutiny; second, I carried out my field analysis in such a way that another researcher could, in theory, analyse the data and draw comparable Primary Health Care Research \& Development 2018; 19: 64-76 
conclusions. As mentioned, I triangulated the data by utilising more than one method of data collection (FGDs, SSIs and POs). In addition, I crossvalidated the data by sending some transcribed versions of the transcripts back to the respondents to ask whether my interpretations were accurate (Robson, 1993). They agreed that the transcripts were a true reflection of records.

To further ensure the degree of validity and reliability, I followed a consistent approach in data collection, recording and documentation. First, I examined the stability of observations over time. I conducted FGDs and SSIs with different people in different times and places. Second, I employed inter-rater reliability (Denzin and Lincoln, 1994) via checks utilising two independent bilingual translators.

\section{Results}

Four FGDs with HSPs $(n=20)$, three FGDs with district stakeholders $(n=15)$, SSIs with HSUs $(n=20)$ and SSIs with national stakeholders $(n=20)$ were carried out. Respondents were aged between 16 and 64 years with the mean age 40 years. Interviews took an average of $1.5 \mathrm{~h}$ and no one refused to be interviewed. The analysis allowed me to obtain 248 computer-generated NVivo10 nodes, which were related to the different dimensions of decentralisation and its impact on district health services, as well as the aspects affecting the decentralisation process. Two data coders were involved in this study. From this analysis it was possible to obtain two broad categories: positive and negative aspects of decentralisation related to access, quality, planning, supplies, coordination and supervision, and participation of PHC services at local levels (Figure 2).

\section{Positive experiences}

\section{Planning and participation}

It was clear that participants on the whole were involved in the planning and participation in the services their local health systems offered. Several respondents stated that they now accessed/utilised the local health services more than before in the community, and they also reported that local residents were more aware about their health and well-being. This perspective was reflected by both national stakeholders (policy-planners and decision-makers) and recipients of services interviewed in the study. For example, a health policy-planner stated, 'There were some initiations of bottom-up health planning involving all stakeholders; people have now more developed their ownership' (50-year-old male, national stakeholder). A member of a health management

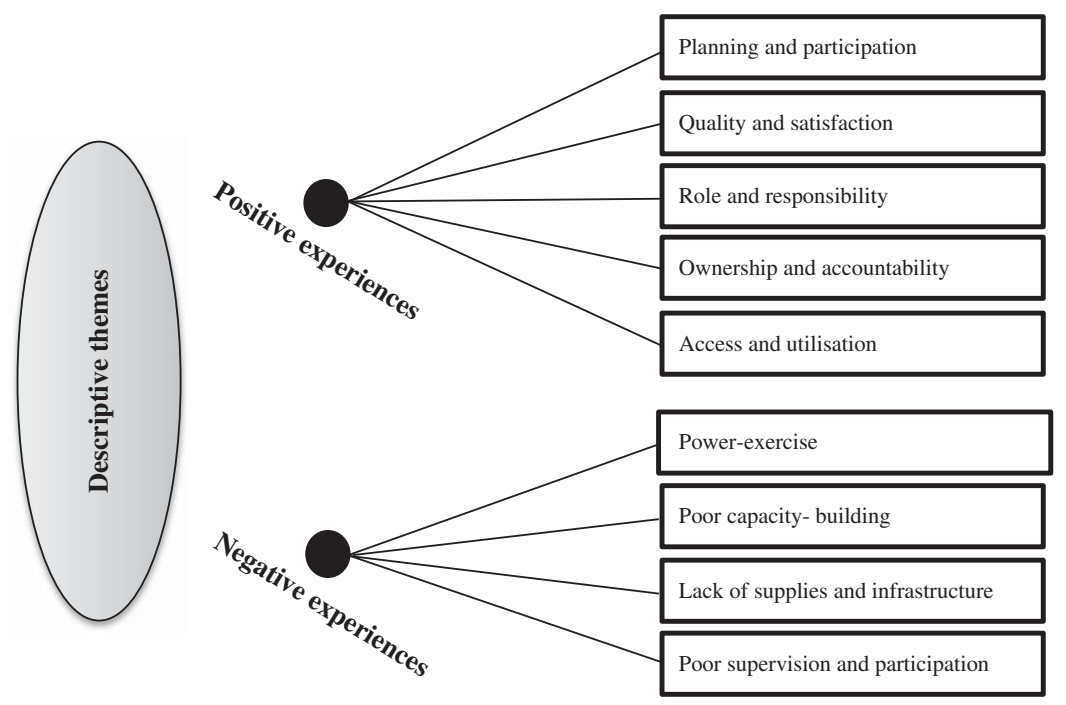

Figure 2 Final lists of descriptive themes

Primary Health Care Research \& Development 2018; 19: 64-76 
committee said, 'Services are delivered from the village level, as if you develop the village-based programme, they will have more knowledge about their problems and concerns so that it would be much easier to solve them. [A b]ottom-up approach - will help to assess and identify local problems' (45-year-old male, district stakeholder). On the same topic, another respondent stated his view:

Yes, I have been involved in planning and conducting of outreach clinic (ORC) clinics in the village several times as [a] community health volunteer. People recognise us well, giving more value so I feel more honour. (37-year-old female, HSP)

\section{Quality and satisfaction}

With reference to the quality of and satisfaction with the services they received, several respondents provided positive feedback. A female patient described her positive experience while visiting local health services:

I got the service on the same day that I asked for. Health professionals are very appropriate to resolve most of my own and family problems, and they are very friendly - easily approachable. (45-year-old female, HSU)

A male patient highlighted that the healthcare service he got was very good and very memorable, as he described he was there almost two weeks ago with the problem of snake bite. When he reached the PHC, the health professionals put his leg in colour water (potassium permanganate) for $12 \mathrm{~h}$. Initially he thought that he would die, but in fact he got fantastic care from them as they were like his god (16-year-old male, HSU).

Yet, another female patient stated:

Offered very [good] quality services and health workers often requested follow-up visits; very good indeed as compared to 5-7 years ago. Always full numbers of health workers delivered health services from newly-constructed buildings; there were five beds for the in-patients, free services, [and an] ambulance for the referral/emergency cases. Good investigation and treatment facilities with friendly care; I liked it. (25-year-old female, HSU)
Participants on the whole noted the improvement of services from years past, which contributed to their satisfaction level.

\section{Role and responsibility clarity}

Several respondents noted that because they had more clarity about the roles and responsibilities of central and local governments in terms of accountability and resource allocations, local health plans could be developed and implemented more inclusively. Local health policies and procedures were now in place and, therefore, systems were more proactive in being guided by the needs and experience of local people. One district stakeholder, for example, reported:

[There] is now better coordination between [the] District Development Committee and District Health Office in terms of planning and resource-sharing (funds); as a result there [are] some improvements on patients' attendance. (64-year-old male, district stakeholder)

\section{Ownership and accountability}

Several service providers noted that decentralisation would bring developed community ownership. The local medical director/healthcare in-charge, for example, described his positive experience and feeling about the community ownership and accountability:

Decentralisation has provided some space to health workers for making healthcare decisions. Because the local authority is an independent entity, we are now able to devolve or generate some revenues at [a] local level. As a result, local people, including political parties, are more accountable to health programmes, which was never the case in the past. (40-yearold male, HSP; 32-year-old male, HSP; 36-year-old female, HSP)

Developing and implementing health services based on local needs fostered more accountability on the part of the consumer.

\section{Access and utilisation}

Some respondents noted that local health policies or programmes were made based on their (users') needs and experience (people-centred Primary Health Care Research \& Development 2018; 19: 64-76 
health services), and essential services were available at the local level. A female patient said:

Easy to come and get it and most of the services [are] completely free. Poor people who can't afford private clinic can access these services without any costs. We are very happy. Medicines are available throughout the year. (34-year-old female, HSU)

A male patient stated the increased availability of basic medicines throughout the year. He added:

And they are much cheaper even if we required purchasing. Even x-rays and lab facilities exist in the village that made our life much easier, both cost- and time-wise. (28-year-old male, HSU)

\section{Negative experiences}

\section{Power-exercise}

Despite the aforementioned positive experiences, there were several concerns about decentralisation raised by study participants. One such concern involved collaboration power-sharing. One national stakeholder, for example, forcefully pointed out that though decentralisation is considered to be a fairer governance system, 'political representatives often reflected their parties' vested interests at a local level; as a result they often make decisions based on their interests. Sectoral operational working/service plans, particularly the monitoring and auditing, were not clearly defined' (48-year-old male, national stakeholder). It is important that in decentralisation, collaboration is crucial between central and local governments, and even at the central Ministry of Health and Ministry of Local Development levels, and that needs to be clearly laid out. There are still, however, some issues which appear with regard to the role and responsibilities - who does what and who has what at the central and local health levels. Power-exercise was mostly used at central levels. The same sentiments were also shared by other study participants, that power-sharing has jeopardised role identification and clarification, both at the strategic and operational levels, in terms of planning and execution of healthcare at the local levels.

Primary Health Care Research \& Development 2018; 19: 64-76

\section{Poor capacity-building}

Respondents noted concerns about the strategic decisions on location, governance structure, and capacity development, which was the case more often with national-level health stakeholders. According to one health policy-planner:

[The] focal point of health sector decentralisation [is] not identified, for example, whether the National Planning Commission (a national apex body) or the Ministry of Health. There was also limited provision of capacity development at national and local levels. Also [there was] not clearly defined governance and political structure, and their role in the public sector [was not defined]. (56-year-old male, national stakeholder)

On the same topic, a health worker respondent stated:

Some policies exist only in papers, but [there are] not clearly defined roles of local health authorities. As a result there is always conflict [concerning] who does what, who has what, and who gains and loses as a result. There are always poor/inadequate provisions of healthcare monitoring and auditing in place. Similarly, there is a lack of local-level health and wellbeing plans. (39-year-old female, HSP)

A similar concern was raised by one service user:

There were poor financial mechanisms, mainly fund flow systems from the central government to local level to local health facilities. As a result, several needs-based health plans were not implemented, nor did they reflect poor people's needs and interests in the programme planning and management cycle. (32-year-old female, HSU)

HSUs and HSPs alike noted concerns related to capacity-building brought about as a result of decentralisation.

\section{Lack of supplies and infrastructure}

Challenges related to supplies was a stated theme. Some healthcare providers described that in healthcare services there were insufficient 
medicines throughout the year, so people cannot provide better services to poor people.

Because poor people cannot afford to purchase some medicines from [the] health centre as they don't have any budgets at the local level, they cannot provide every service, so we failed to address the needs of poor people. (41-year-old male, HSP; 38-year-old female, HSP)

They further highlighted that though they have decided in the management committee to open up 24-h 'obs and gynae delivery' services, because of the lack of infrastructure and financial support, they could not manage this. The chair of the health service management committee described his struggles with health infrastructure: 'We didn't [even] have any extra room for the patients'. Fear of lack of regular supplies, mainly essential medicines, was a recurrent explanation for poor-quality services (51-year-old male, district stakeholder).

\section{Supervision and participation}

Concerns about the supervision of, monitoring of and participation in local health services were also noted. One respondent described that:

There is a poor supervision and support mechanism between the district [District health office] and primary healthcare centre; therefore, it is difficult for me being an in-charge centre to assure the community that they will get what they demand. In fact I often felt reluctant to talk [to] the local people about their health needs. (37-year-old female, HSP)

Participation, on the whole, appeared relatively nominal. While some people were involved in the planning and management levels, the people who were poor and marginalised were often left out. A medical doctor, for example, lamented:

I would like to [be] involved [by] shar[ing] my voice in the health centre as I [am] never ever invited for the general meeting. (48-year-old male, HSP)

Similarly, an elderly patient shared:

I am a member of Kisan Samuha (farmers' group). I am a member of Adibasi (indigenous) women's group, and promoting vegetables and nursery gardens [is] the major [job] of the group. I would like to engage myself in the community health works. I am also a member of one women's group and my sister-in-law is a community health volunteer, for tuberculosis. I want to work with these health workers, especially in the sector of water, health and sanitation, and environmental health. No, I don't know how to join in as I was never invited to become a community health member. (43-year-old male, HSU)

\section{Discussion}

In this study, I found that the idea and practice of decentralisation indicates that the body of locally elected officials who represent the local government or local political unit would be a viable institution to which power and authority can be devolved. This notion holds some important implications, based on the findings of the study that local political authorities are close to local communities and can therefore best represent their interests. Local community involvement ultimately increases the effectiveness, efficiency and responsiveness of interventions (see Cheema and Rondinelli, 1983; Regmi et al., 2010).

Similar to previous studies (see Bossert, 2000; Bossert and Beauvais, 2002; Bossert et al., 2003; Collins and Omar, 2003; Omar et al., 2007; Sreeramareddy and Sathyanaraya, 2013; Mohammed et al., 2015), the findings of this study have supported the claims that decentralisation of PHC services through devolved power and authority are seen as beneficial. In particular, local health facilities are gaining some degree of freedom from the central government. Local officials are being held accountable to people's needs and interests, recognising consumers' voices and choices by health systems, and engaging in participatory service planning and management, as well as health service performance. Additionally, poor and excluded members of the community have clearly recognised the benefits of decentralisation. Similarly, sharing the study findings to the community involving the local HSPs, civil societies and policyplanners, and decision-makers would allow an opportunity to hear what the community have to say, and this dialogue would give HSPs at both ends of the spectrum an opportunity to evaluate their own thinking in service delivery.

Primary Health Care Research \& Development 2018; 19: 64-76 
Notwithstanding the above, this study has also indicated that decentralisation may generate a series of micro-level problems in achieving the objectives of devolution. Omar et al. (2007) supported this view by recognising that decentralisation policy in Nepal is coupled with a faulty transfer system and differing levels of efficiency and capacity, which might also hamper the pursuit of regional and local equity in health service delivery and management, as linking the devolution of authority and power to locally elected government authorities is not a sufficient condition to ensure the participation of civil societies and groups in decision-making processes.

Decentralisation at its best has not been fully reflected in practice in Nepal. This study noted that political representatives were still at the centre of health services plans, and they often reflected their parties' vested interests rather than people's needs and aspirations. In addition, this study highlighted that central government is still in control of all financial aspects, including staff hiring and firing. Roles and responsibilities have not been clearly demarcated between central and local government; and external development partners' (donors') roles have not been made clear in terms of developing and implementing local health programmes and policies. These tendencies run against the grain of decentralisation. Furthermore, some service users felt that there were inadequate reflections of poor people's healthcare needs and interests in programme planning and management due to discrimination by practitioners.

Nepal is still in a transitional phase due to political turmoil and instability. As a result, the local government is not operating within the principles of local governance systems. Nevertheless, recently the Government of Nepal has successfully promulgated the new constitution of 2015. In accordance with law, article 35 has fundamentally recognised that 'each person shall have equal access to healthcare', especially targeting the dalit communities (ie, poor and marginalised people) (Government of Nepal, 2015).

\section{Strengths and limitations}

This study has not only explored some insights into the benefits and disadvantages of decentralisation from the wider stakeholders' perspectives in this

Primary Health Care Research \& Development 2018; 19: 64-76 particular country, but also offers lessons learned to provide researchers or policy-makers fodder for further research in the devolution of the healthcare sector. Imbued in this study were three limitations: first, the central purpose of decentralisation was to increase the coverage, efficiency, equity, effectiveness and quality of health services, thereby improving the health status of the population (Bossert, 1996). However, this study focussed on exploring and examining the effects of decentralisation on provision of PHC services and health service performance from the viewpoints of HSUs and HSPs only.

Second, this study adopted a qualitative-driven mixed method design (QUAL $\rightarrow$ qual), where the qualitative core component was the FGDs, which in theory used 'inductive theoretical drive' with the sequential qualitative supplementary component (SSIs and Os). In theory, a mixed method design would strengthen the research study, but in practice it is not always easy to do (Morse and Niehaus, 2009).

Finally, this study employed the purposive method for sampling. Although the researcher captured a diversity of participants in terms of ethnic source, age, sex, location, services category and role in the community, the sample precluded the identification of those who had no access to or utilisation of the health services.

\section{Conclusion}

In spite of the methodological limitations, the results from this study do make a valuable contribution to our knowledge in terms of understanding and examining healthcare through qualitative-driven mixed methods design using a QUAL $\rightarrow$ qual approach. Qualitative methods are often criticised as a 'second-class science' (Morse, 2006: 315) because findings are related to a specific context; therefore, knowledge obtained from this approach would be difficult to transfer to another context. This study has, however, recognised the effectiveness of qualitative designs in terms of enacting an in-depth understanding of a problem (decentralisation in a third-world country) and exploring possible options within that given context. The findings from the study would be an invaluable source of information that would directly benefit the marginalised community that it seeks to assist. 
For these reasons, I believe that the approach has merit for pursuing additional research (i) to examine and understand the impact of decentralisation on output and outcome objectives - improving equity (access and coverage), efficiency, quality and improving health outcomes, and (ii) to translate its implications across a wider scale involving more PHC services to improve the quality of services, considering the marginalised or excluded groups (women, children, poor religious, cultural and ethnic groups) is now the priority (see Bossert, 1996).

\section{Acknowledgements}

The author thanks all participants who participated in this study.

\section{Financial Support}

This research received no specific grant from any funding agency, commercial or not-for-profit sectors.

\section{Conflicts of Interest}

None.

\section{Ethical Standards}

The authors assert that all procedures contributing to this work comply with the ethical standards of relevant national and institutional guidelines and with the Helsinki Declaration of 1975 , as revised in 2008. The study was approved by the NHRC and UWE ethics committees.

\section{References}

Bossert, T. 1996: Decentralisation. In Jovosky, K., editor, Health policy and system development: an agenda for research. Geneva: WHO, 147-59.

Bossert, T. 2000: Decentralisation of health systems in Latin America: a comparative analysis of Chile, Colombia, and Bolivia. Boston, MA: Health Sector Reform Initiative.

Bossert, T. 2014: Decentralisation of health systems: challenges and global issues of the twenty-first centuries. In Regmi, K., editor, Decentralizing health services: a global perspective. New York: Springer, 199-207.

Bossert, T. and Beauvais, J. 2002: Decentralisation of health systems in Ghana, Zambia, Uganda and the Philippines: a comparative analysis of decision spacing. Health Policy and Planning 14, 14-31.
Bossert, T., Chitah, M.B. and Bowser, D. 2003: Decentralisation in Zambia: resource allocation and district performance. Health Policy and Planning 18, 357-69.

Bowling, A. 2009: Research methods in health: investigating health and health services. Maidenhead: Open University Press.

Bowling, A. and Ebrahim, S. 2005: Handbook of health research methods: investigation, measurement and analysis. Maidenhead: Open University Press.

Bryman, A. 2001: Social research methods. Oxford: Oxford University Press.

Campbell, J. and Holland, J. 1999: Methods in development research: combining qualitative and quantitative approaches. London: ITDG Publishing.

Chambers, R. 1997: Whose reality counts? London: Intermediate Technology Publications.

Cheek, J., Lipschitz, D.L., Abrams, E.M., Vago, D.R. and Nakamura, Y. 2015: Dynamic reflexivity in action: an armchair walkthrough of a qualitatively driven mixedmethod and multiple methods study of mindfulness training in schoolchildren. Qualitative Health Research 25, 751-62.

Cheema, G. and Rondinelli, D. 1983: Decentralisation and development: policy implementation in developing countries. London: Sage Publications.

Cohen, L., Manion, L. and Morrison, K. 2011: Research methods in education. London and New York: Routledge.

Collins, C.D. and Omar, M.A. 2003: Developing health sector decentralisation in Nepal: collaborative policy development. Nepal: British Council/DHSP.

Creswell, J.W., Shope, R., Plano Clark, V.L. and Green, D.O. 2006: How interpretive qualitative research extends mixed methods research. Research in the Schools 13,1-11.

Denzin, N.K. 1978: The research act: a theoretical introduction to sociological methods. New York: McGraw-Hill.

Denzin, N.K. and Lincoln, Y.S. 1994: Handbook of qualitative research. Thousand Oak, CA: Sage.

Denzin, N.K. and Lincoln, Y.S. 1998: Strategies for qualitative enquiry. Thousand Oak, CA: Sage.

Denzin, N.K. and Lincoln, Y.S. 2005: The discipline and practice of qualitative research. In Denzin, N.K. and Lincoln, Y.S. editors, The Sage handbook of qualitative research. Thousand Oak, CA: Sage, 1-32.

Department of Health Services 2014: Revitalizing primary health care country experience: Nepal. Nepal: Ministry of Health, Department of Health Services.

Flick, U. 1998: An introduction to qualitative research. London: Sage.

Government of Nepal 2015: Constitution bill of Nepal 2015. Revised draft. Kathmandu, Nepal: Constitution Drafting Committee Constituent Assembly Secretariat.

Gray, D. 2004: Doing research in the real world. London: Sage.

Green, J. and Thorogood, N. 2014: Qualitative methods for health research. London: Sage.

Greene, J.C. 2006: Towards a methodology of mixed-methods social inquiry. Research in the Schools 13, 93-98.

Primary Health Care Research \& Development 2018; 19: 64-76 
Hennink, M. 2007: International focus group research: a handbook for the health and social sciences. London: Routledge.

Hesse-Biber, S. 2010: Emerging methodologies and methods practices in the field of mixed methods research. Qualitative Inquiry 16, 415-18.

Hesse-Biber, S. and Johnson, R.B. 2013: Coming at things differently: future directions of possible engagement with mixed methods research. Journal of Mixed Methods Research 7, 103-9.

Jiménez-Rubio, D. 2011: The impact of decentralization of health services on health outcomes: evidence from Canada. Applied Economics 43, 3907-17.

Johnson, R.B., Onwuegbuzie, A.J. and Turner, L.A. 2007: Toward a definition of mixed methods research. Journal of Mixed Methods Research 1, 112-33.

Litvack, J., Ahmad, J. and Bird, R. 1998: Rethinking decentralisation in developing countries. Washington, DC: International Bank for Reconstruction and Development/World Bank.

Mason, J. 2002: Qualitative researching. London: Sage.

Mays, N. and Pope, C. 1996: Quality in qualitative health research. In Pope, C. and Mays, N., editors, Qualitative research in healthcare. London: Blackwell Publishing Ltd, 82-101.

Mohammed, J., North, N. and Ashton, T. 2015: Decentralisation of health services in Fiji: a decision space analysis. International Journal of Health Policy and Management 5, 173-81.

Morgan, D. 1998: Practical strategies for combining qualitative and quantitative methods: Application to health research. Qualitative Health Research 8, 1034-38.

Morse, J.M. 2003: A review committee's guide for evaluating qualitative proposals. Qualitative Health Research 13, 833-851.

Morse, J.M. 2006: It is time to revise the Cochrane criteria [Editorial]. Qualitative Health Research 16, 315-17.

Morse, J.M. and Cheek, J. 2014: Making room for qualitativelydriven mixed-method research. Qualitative Health Research 24, 3-5.

Morse, J.M. and Cheek, J. 2015: Introducing qualitativelydriven mixed- method designs. Qualitative Health Research 25, 731-33.

Morse, J.M. and Niehaus, L. 2009: Mixed method design: principles and procedures. Walnut Creek, CA: Left Coast Press.

Newell, R. 1996: Reliability and validity. Nurse Researcher 3, 16-26.

O'Cathain, A., Murphy, E. and Nicholl, J. 2008: The quality of mixed methods studies in health services research. Journal of Health Services Research and Policy 13, 92-98.

Omar, M.A. 2003: Health sector decentralisation in: unique or universal. World Hospitals and Health Services 38, 24-30.
Omar, M.A., Collins, C., Adhikari, D., Dhakal, M., Thapa, D. and Emmel, N. 2007: Health system decentralisation in Nepal: identifying the issues. Journal of Health Organisation and Management 21, 535-45.

Onwuegbuzie, A.J. and Johnson, R.B. 2006: The validity issue in mixed method research. Research in the Schools 13, 48-63.

Patton, M. 2002: Qualitative research and evaluation methods. Thousand Oaks, CA: Sage.

Pawson, R. and Tilly, N. 1997: Realistic evaluation. London: Sage.

Peckham, S., Exworthy, M., Powell, M. and Greener, I. 2006: Decentralisation as an organisational model of healthcare in England. London: SDO.

Phillips, C.B., Dwan, K., Hepworth, J., Pearce, C. and Hall, S. 2014: Using qualitative mixed methods to study small health care organizations while maximising trustworthiness and authenticity. BMC Health Services Research 14, 559.

Porcelli, F. 2009: Fiscal decentralisation and efficiency of government. A brief literature review. Retrieved 7 October 2016 from http://www2.warwick.ac.uk/fac/soc/economics/ staff/fporcelli/dec_efficiency_gov.pdf

Regmi, K. 2013: Triangulation in healthcare research: what does it achieve? London: Sage.

Regmi, K., Naidoo, J., Greer, A. and Pilkington, P. 2010: Decentralisation and district health services in Nepal: understanding the views of service users and service providers. Journal of Public Health 32, 406-17.

Ritchie, J. and Lewis, J. 2003: Qualitative research practice: a guide for social science students and researchers. London: Sage.

Roberts, M.J., Hsiao, W.C., Berman, P. and Reich, M.R. 2004: Getting health reform right: a guide to improving performance and equity. New York: Oxford University Press.

Robson, C. 1993: Real world research: a resource for social scientists and practitioners researchers. Oxford: Blackwell Publishers.

Sale, J.E. and Brazil, K. 2004: A strategy to identify critical appraisal criteria for primary mixed method studies. Quality \& Quantity 38, 351-65.

Seale, C., Giampietro, G., Jaber, F.G. and David, S. 2004: Qualitative research practice. London: Sage.

Silverman, D. 2010: Doing qualitative research. London: Sage.

Sreeramareddy, C.T. and Sathyanaraya, T.N. 2013: Decentralised versus centralised governance of health services. London: The Cochrane Library.

Teddlie, C. and Yu, F. 2007: Mixed methods sampling: a typology with examples. Journal of Mixed Methods Research 1, 77-100.

Tylor, S.J. and Bogdan, R. 1998: Introduction to qualitative research methods: a guide book and resource. New York: John Wiley and Sons.

World Health Organization 2014: Providing health intelligence to meet local needs: a practical guide to serving local and urban communities through public health observatories. Geneva: WHO. 